\title{
Understanding individual responses to failure by the organisation to fulfil its obligations: examining the influence of psychological capital and psychological contract type
}

\author{
Wayne O'Donohue, \\ Department of Employment Relations and Human Resources, Griffith University \\ Contact email:w.odonohue@griffith.edu.au \\ Angela Martin, \\ School of Business and Economics, University of Tasmania \\ Nuttaneeya (Ann) Torugsa, \\ Australian Innovation Research Centre, University of Tasmania
}

\begin{abstract}
:
This study advances both psychological contract (PC) and psychological capital (PsyCap) research by testing a novel theoretical model predicting likely worker response, as a joint function of an individual's level of PsyCap and PC type, to perceived failure by the organisation to meet its obligations to the worker-organisation relationship. With a large emergency services organisation using volunteer workers as the research context, the study presents the first empirical evidence from a sample of 592 volunteers that the integrated application of PC and PsyCap theory can contribute to a better understanding of individual responses to an organisation's failure to affirm ongoing support for the volunteerorganisation relationship.
\end{abstract}

Keywords: psychological capital; psychological contract; volunteers; emergency services

Please cite this article as:

O’Donohue, W., Martin, A. \& Torugsa, N. A. (2015) Understanding individual responses to failure by the organisation to fulfil its obligations: examining the influence of psychological capital and psychological contract type. Human Resource Management Journal. 25: 1, 131 147. 


\section{INTRODUCTION}

A well-established construct for better understanding the exchange that characterises the worker-organisation relationship is that of the 'psychological contract' (PC), i.e. the individual worker's subjective understanding of obligation-based exchanges with the organisation (Conway and Briner, 2009). While PC research has identified individual differences (e.g. Edwards et al., 2003; Raja et al., 2004) as important factors shaping the worker-organisation relationship, new research possibilities are emerging from recent research investigating four positive psychological attributes - self-efficacy, hope, optimism and resilience - that form a broader concept called 'psychological capital' (PsyCap) (Luthans et al., 2004). There have been no published studies relating the two concepts, and none examining their joint impact on a worker's response to perceived failure by the organisation to meet its commitment to the worker-organisation relationship. Hence, our study aims: to advance PC and PsyCap research by testing a novel theoretical model predicting likely worker response, as a joint function of an individual's level of PsyCap and PC type; and by locating our study in the volunteer context, to publish the first empirical evidence that the joint application of the two constructs can contribute to a better understanding of the consequences of a perceived failure by the organisation to affirm its ongoing support for the volunteer- organisation relationship.

First, we overview the two constructs and associated empirical research before presenting a unique theoretical model and four hypotheses. Discussion of the study method, analysis and results then follow. The article concludes with discussion of the findings, their implications, study limitations and future possible research directions.

\section{PCs}

As commonly defined, the PC comprises an individual worker's beliefs about a reciprocal agreement involving economic and socio-emotional obligations that results from promises perceived as having been exchanged with the organisation (Rousseau, 1995). Research has underscored that, from the individual's perspective, a functional PC requires ongoing fulfilment of obligations by the organisation, with meta-analyses (Bal et al., 2007; Zhao et al., 2007) showing that when the organisation is perceived to have failed in this regard, negative impacts such as reduced performance, satisfaction and commitment occur. Several points of interest follow from this research. First, while negative effects have been identified, many of the reported correlations are weak to moderate (Suazo et al., 2005). Second, every instance of perceived non-fulfilment by the organisation does not produce a negative response from the individual (Zhao et al., 2007). Third, while the 'PC literature is filled to the brim' with studies examining individual responses to non-fulfilment, all but one (Starnes, 2007) have been conducted in the paid work context (Vantilborgh et al., 2014). Taken together, these points suggest that there may be unaccounted factors, such as individual psychological differences, influencing the individual's response, and indicate that there is an important research gap in the literature.

In this light, our study focuses on the response intention individual volunteers might be expected to form after cognition by the individual that the organisation has not 'lived up to its side of the deal'. The concepts of 'breach' and 'violation' or the process leading up to and including cognition of non-fulfilment are not a focus of study here; these topics have already been examined at length in the literature (Conway and Briner, 2009). 


\section{PC theory and volunteers}

Research clearly supports the usefulness of PC theory in the volunteer work context (Nichols, 2013; Scheel and Mohr, 2013). Theoretically, the PC concept is not just applicable to promissory-based exchange between paid employees and employers. Rousseau (1995), whose definitional approach is most widely used, theorised the concept as applicable to a variety of contexts, people and working relationships. From this starting point, Farmer and Fedor (1999) argued the PC can, therefore, be interpreted as embracing the volunteerorganisation relationship. Support for this interpretation is provided by Thompson and Bunderson's (2003) extension of Rousseau's conceptual framework to incorporate a valuesbased content focus, consisting of 'ideology-infused' obligations reflecting a shared commitment by the individual and organisation to a valued social cause, and Scheel and Mohr's (2013) conceptualisation of volunteering as not just leisure but as work in the sense of a productive occupation and a form of employment relationship.

Empirical research examining the application of PC theory to volunteering is still in its infancy (Vantilborgh et al., 2014). An early study of a large non-profit organisation (Farmer and Fedor, 1999) concluded that the volunteer PC shares characteristic features with that of the paid worker. Other research across a range of volunteer settings supports this conclusion (e.g. Taylor et al., 2006; Nichols and Ojala, 2009; Vantilborgh et al., 2011, 2012). Empirical research has also identified content similarities with paid workers, although with a different emphasis revealed. For example, like paid workers, volunteers perceive the organisation to have economic obligations (with the obvious exception of payment for work); however, there is greater emphasis on the organisation's socio-emotional obligations, such as caring about volunteers' well-being and recognising volunteers' contributions to the organisation (e.g. O’Donohue and Nelson, 2009). Also, given personal values often provide the motivation to volunteer, and many volunteers choose an organisation because they share at least some common values (Clary et al., 1998), there is some evidence that the contents of the volunteer PC can include values-based obligations (e.g. Vantilborgh et al., 2011, 2012; Scheel and Mohr, 2013). However, such evidence is not yet conclusive (Nichols, 2013), nor is the evidence clear on which particular economic and socio-emotional obligations are characteristic of the volunteer PC (Nichols and Ojala, 2009). Also, as noted above, there is a lack of empirical research in the volunteer context examining responses to non-fulfilment of obligations, representing an important gap in the literature to which this article makes a contribution.

\section{Classifying PC types}

The most commonly used typology for classifying contract type (Rousseau, 1995) uses two contract models as its basic interpretative elements - 'transactional PC' (TrPC) and 'relational PC' (RelPC) - defined by a set of generic contract features (see Table 1).

\section{Insert TABLE 1 Interpretive framework for psychological contracts}

The characteristic features of the TrPC type are an economic content focus, relative stability and limited flexibility, and specific defined time-bound exchange. Such contracts assume rational and self-interested parties, with no ongoing interdependence between parties. The RelPC type is more complex and has the characteristic features of a socio-emotional content focus, with evolving contributions that represent mutual investments from which withdrawal is difficult, a commitment to the other party that promotes interdependence, a relative openended time frame, less specific content terms and a lesser requirement for immediate reciprocity (McLean Parks and Smith, 1998). 
As discussed above, while it is possible that a PC may include reciprocal values-based obligations, there is no agreement yet on whether it is, or is not, a conceptually distinct third type of contract. Therefore, Table 1 shows ‘ideology-infused' exchange as a variation on either the TrPC or RelPC, with some features (content focus, salient beneficiary, and organisational and individual obligations) reflecting values-based obligations. Integrating such exchange into the bidimensional typology is consistent with Thompson and Bunderson's (2003) conceptualisation, and also recognises that values-based obligations would be additional to the economic and socio-emotional mix that either type of PC would usually include. This latter point concerning the usual mix of content items raises an important and often-overlooked aspect of the typology, i.e. it is a typology for classifying contract type and not content focus. ${ }^{1}$

As shown in Table 1, PC type is determined using six generic contract features - salient beneficiary, scope and tangibility, stability and duration, content focus, organisational obligations, and individual obligations - on a continuum anchored at one end by the wholly TrPC type and at the other by the wholly RelPC type. In theory, a continuum allows three possible classifications: either one of the two polar types, or some balance between the two types. Given empirical research has demonstrated that an individual's PC will usually include a mix of content items (Conway and Briner, 2009), it is unlikely that an individual's PC will have features characteristic of only one type. It is more likely that a PC will reflect an idiosyncratic combination of both types of contract features, but with one predominating type. In this light, given the consensus that Rousseau's (1995) typology has been fundamental in increasing knowledge of how and why workers respond when they perceive the organisation to have not met its PC obligations (Conway and Briner, 2009), the bidimensional typology is used here for classifying contract type not as wholly one or the other, but as either 'predominantly relational' (PreRelPC) or 'predominantly transactional' (PreTrPC).

\section{PSYCHOLOGICAL CAPITAL}

The PsyCap concept is a higher order construct that combines four positive attributes that characterise an individual's psychological state which influences productivity: (a) hope persevering towards goals and when necessary redirecting paths to goals, (b) optimism making positive attributions about succeeding now and in the future, (c) resilience - bouncing back (and even beyond) when beset by problems or adversity and sustaining effort to achieve success, and (d) self-efficacy - believing in own ability to put in the necessary effort to succeed at challenging tasks. Unlike traits, these attributes are held to be state-like; i.e. they are relatively less fixed and more dynamic in nature, but not as transient as mood states, and as such are open to development and management for performance improvement purposes (Larson and Luthans, 2006). Shared similar coping mechanisms (Avey et al., 2011) form the basis for the synergistic effect that the higher order PsyCap construct appears to have, judging by reported empirical evidence showing that the overall measure of PsyCap produces higher correlations with performance outcomes than its individual components independently (Luthans et al., 2007a). Such findings are consistent with psychological resource theory,

\footnotetext{
${ }^{1}$ Note 1 . The terms transactional and relational have been used in the PC literature as descriptors for two different concepts: (a) content focus, i.e. a specific contract feature; and (b) contract type, i.e. a broader summary set of six contract features. In order to retain conceptual clarity for this study, and consistent with Rousseau's (1995) conceptual framework, we use the terms transactional and relational solely as descriptors of contract type, and use the terms economic and socio-emotional as descriptors of the content focus identified as characteristic of each contract type, respectively.
} 
which states that some constructs are indicators of broader, multidimensional 'core' factors, which aid individuals in producing favourable outcomes (Winkel et al., 2011). Furthermore, as noted by Bandura (2006), an agentic perspective of human behaviour and positive psychology would cast employees' PsyCap as a motivational mechanism associated with proactive striving for success.

In comparison to the PC, research into PsyCap is in its infancy with only a small but growing number of published empirical studies. A recent meta-analysis of 51 research samples (Avey et al., 2011) showed significant relationships between PsyCap and employee attitudes such as job satisfaction, commitment and turnover intentions, and employee behaviours such as citizenship behaviour and job performance. However, to the best of our knowledge, there are no published empirical studies of the impact of PsyCap on responses by volunteers to adverse circumstances in the workplace impacting on the volunteerorganisation relationship.

\section{THEORETICAL MODEL AND HYPOTHESES}

The exit, voice, loyalty and neglect (EVLN) framework (Hirschman, 1970) is well established as a means for framing individuals' responses to perceived non-fulfilment of obligations by the organisation (Conway and Briner, 2009). The underlying logic is that responses can be characterised using two dimensions: 'active/passive', where a distinction is drawn at the level of directness and effort of the individual's response; and 'constructive/destructive', where a distinction is made in the nature and extent of the impact on the individual-organisation relationship. Using these two dimensions, there are four possible response types: (a) exit - an active, destructive response through which self-interest is prioritised, and which includes thinking about leaving or quitting the organisation, (b) voice - an active, constructive response that promotes joint interest, and which includes reporting problems and participating in problem-solving groups, (c) loyalty - a passive, constructive response aimed at maintaining the existing relationship with the organisation, and which includes waiting patiently and trusting in the organisation to solve the problem in the joint interest, and (d) neglect - a passive, destructive response placing little value on a relationship, and which includes reducing work effort and contribution to the organisation. While responses of each type may occur singly, or individuals may move sequentially from one to another (Naus et al., 2007), this study focuses only on the likely initial response.

By drawing on the literature, we use the EVLN typology to frame a theoretical model (see Figure 1) that uses predominant PC type and PsyCap level as independent variables to predict a response (dependent variable); specifically, predominant PC type predicts a constructive or destructive response, while PsyCap level predicts an active or passive response. The underpinning logic is that neither independent variable is sufficient by itself to predict any of the specified responses, but using the two variables together joins the constructive/destructive and active/passive dimensions, thus making the prediction of a specific response intention possible. It is important to note that using the two independent variables together in this way does not necessarily imply a moderation effect, which may or may not occur.

\section{Insert FIGURE 1 Relating predominant psychological contract type and level of psychological capital to EVLN responses}

\section{Linking PC type with constructive/destructive responses}

Empirical evidence consistently demonstrates that if an individual believes a relationship to have positive value, then this will result in relationship-building behaviours and vice versa 
(Conway and Briner, 2009). In the case of an individual with a PreRelPC, there is affective commitment to the organisation and willingness to trust the organisation to honor its obligations, which will emphasise socio-emotional contributions based around joint interests. A sense of 'give and take' operates in regard to reciprocity, and delays (within acceptable bounds) in fulfilment of obligations by the other party are tolerated. As trust is the basis for the relationship (Rousseau, 1995), individuals with a PreRelPC are more likely to contribute in order to ensure the relationship survives. In other words, in the event of non-fulfilment, such individuals are more likely to stay with the organisation and cooperate through the constructive behaviours of voice and loyalty (McLean Parks and Smith, 1998). In contrast, exit and neglect responses are more likely to associate with non-fulfilment of a PreTrPC where the overall emphasis is on self-interest and a lesser emphasis applies to the relationship (Rousseau, 1995). A primary focus on short-term economic exchange that is more specific and closely monitored makes non-fulfilment typically more unambiguous. Moreover, as exchanges under a PreTrPC are frequently measured as costs rather than as investments, the individual has a lesser interest in strengthening the relationship with the organisation over the long term. Thus, such individuals are more likely to respond to non-fulfilment through the destructive behaviours of exit and neglect.

\section{Linking PsyCap with active/passive responses}

As noted, PsyCap has four specific attributes as its constituent elements. Hope is evident when an individual not only has motivation to pursue goals ('willpower'), but can also generate multiple pathways to achieve goals ('waypower') (Snyder and Lopez, 2002). In other words, individuals with hope have willingness, energy, and ways and means to achieve their goals, and when plans are blocked they are able to generate viable alternative ways and means to move forward. Optimism exists when individuals have a personal explanatory style that attributes positive outcomes to internal efforts and enables them to contribute proactively to goal achievement. In the case of negative events, they tend to attribute them to external causes, thus avoiding guilt and self-blame, which helps maintain a positive, optimistic outlook (Snyder and Lopez, 2002). Resilience is the capacity of an individual to cope with and adapt positively to significant and possibly extreme events that impact (negatively or positively) on the individual's circumstances. As such, resilience is a reactive rather than proactive attribute, and may therefore be enhanced each time an individual overcomes and recovers from negative factors such as failure and conflict, or copes and adapts positively to progress and increased responsibility. Resilient individuals are more likely to display selfregulation, social competence, problem-solving skills and the capacity to deal with ambiguity through a well-developed sense of purpose (Masten, 2001). Last, in relation to PsyCap, selfefficacy is viewed as a domain-specific state related to work performance, rather than as a generalised trait (Luthans et al., 2008). It is most evident when an individual believes he/she has the motivation, cognitive resources and plan needed to complete a task. Such individuals are more likely to welcome challenging tasks and roles in which they are able to invest their energy, and persist until completing the task. An individual's self-efficacy is enhanced and reinforced through goal achievement, learning from experience, positive feedback from salient others, and the enjoyment of physiological and psychological wellness (Bandura, 2006).

There is limited but persuasive empirical research suggesting those individuals who have high levels of each of the four PsyCap elements, rather than a high level of just one of the elements or low levels of the elements, will consistently be more active, expend more effort, manoeuvre obstacles more effectively, expect success and cope with setbacks more readily (Avey et al., 2011). In other words, individuals with higher levels of PsyCap are more likely to respond to non-fulfilment in an active fashion, thus tending towards exit and voice 
behaviours ahead of the passive behaviours of loyalty and neglect, which individuals with lower levels of PsyCap might favour. The supporting empirical evidence for this reasoning can be found, for example, in studies demonstrating that PsyCap has a relationship to active job search strategies in retrenched professionals (Chen and Lim, 2012), partially mediates the effect of job stress on turnover intentions (Avey et al., 2009), equips individuals with the ability to cope with negative workplace experiences (Jackson et al., 2007) and mitigates the effects of negative work experiences on commitment to work (Laschinger and Grau, 2012). PsyCap has also been shown to associate with problem-focused coping (Khan et al., 2011), and the ability of individuals to separate themselves from the negativity of unfavourable situations, create pathways to goal achievement, and exhibit flexibility and persistence when faced with hardship or significant change (Luthans and Youssef, 2004).

\section{Hypotheses}

Based on the preceding discussion and our theoretical model (see Figure 1), we derive four hypotheses for testing. First, when the individual has a PreRelPC, the relationship with the organisation is prioritised. When such individuals have a high level of PsyCap, they will have high expectations regarding the potential for resolving a problem, and a strong belief in their own ability to sustain a mutually productive relationship. Hence, such individuals are more likely to see an opportunity to engage in voice, active and constructive behaviours aiming at restoring the individual-organisation relationship.

\section{Hypothesis 1: Individuals with a PreRelPC and high PsyCap are more likely to respond initially to non-fulfilment through voice.}

Second, when the individual has a PreTrPC, the individual is less willing to accept delay in satisfying the need for reciprocity; self-interest rather than maintaining the individualorganisation relationship is prioritised. When such individuals are high in PsyCap, they will have a strong belief in their ability to protect their interest and obtain alternative work elsewhere that meets their needs. Hence, self-interest, self-confidence and the lack of value placed on the relationship make likely an active and destructive response through exit.

\section{Hypothesis 2: Individuals with a PreTrPC and high PsyCap are more likely to respond initially to non-fulfilment through exit.}

Turning now to our third and fourth hypotheses, which consider individuals with low levels of PsyCap, we posit that they are likely to respond in a more passive manner than their high PsyCap colleagues, tending towards the behaviours of loyalty and neglect. For individuals with a PreRelPC, preserving the relationship with the organisation will have priority, thus making likely a constructive response aiming at limiting further damage to the relationship. However, because individuals with low PsyCap lack a strong belief in their own ability to contribute actively, they are likely to exhibit good will towards the organisation with a passive response of loyalty.

\section{Hypothesis 3: Individuals with a PreRelPC and low PsyCap are more likely to respond initially to non-fulfilment through loyalty.}

On the other hand, under a PreTrPC, the individual's response is unlikely to reflect a perception that the current individual-organisation relationship is worth preserving. An individual with low PsyCap will lack confidence in his/her ability to get another job and/or to communicate with the organisation regarding his/her needs. Hence, such individuals are more 
likely to focus on protecting self-interest at a cost to the organisation's interest, with the destructive response of neglect.

Hypothesis 4: Individuals with a PreTrPC and low PsyCap are more likely to respond initially to non-fulfilment through neglect.

\section{METHOD}

\section{Sample}

The study sample was drawn from a large Australian public sector emergency management organisation that helps urban and rural communities in a diverse range of emergency and disaster situations, such as cyclones, floods, bushfires, road/rail/air crashes, searches for missing persons and crime scene forensic searches. For such work, formal management processes are essential because the work can require performance of potentially lifethreatening tasks, and often demands extraordinary physical and psychological resources and coping efforts (Thormar et al., 2010). The participating organisation has a total of over 6,400 volunteers responsible for the delivery of special emergency services, managed by a small core of employees using a range of professional HR management practices covering recruitment and retention, performance management, training and development, and volunteer engagement, well-being and safety.

The study involved empirical testing of the hypotheses using survey data collected from volunteers in a simple random selection of 172 of the organisation's 290 operational units. The survey was administered with the cooperation of the organisation's counselling and support programme. The survey package (including the questionnaire, a project information sheet and a reply-paid addressed satchel) was administered by mail to the randomly selected units (our survey distributors), with a total of 83 units (2,297 volunteers) confirming receipt of the package. After responses with missing data were eliminated, a total of 592 volunteers remained in the sample, resulting in a response rate of 25.8 per cent. Of all respondents, 63.1 per cent were aged over 40, 56.3 per cent were males, 47.1 per cent had less than 5 years of volunteering experience, and 51.1 per cent had service with the organisation of less than 5 years.

Non-response bias was assessed through Armstrong and Overton's (1977) time-trend extrapolation procedure, where the responses from 'early' respondents were compared with those from 'late' respondents using demographic variables (age, gender, and years of volunteering and service) along with dependent variables (EVLN). The analysis showed no statistically significant difference between early and late respondent groups on any of these variables.

\section{Measures}

A shortened version of the Psychological Contract Scale (PCS), originally developed by Millward and Hopkins (1998) for measuring the transactional/relational distinction in contract type, was used (see Raja et al., 2004, for discussion of scale's psychometric properties). Our survey instrument comprised seven items to measure the RelPC type and ten items to measure TrPC type. The PCS was pretested for content validity with the organisation's senior volunteer management. The pretest resulted in only minor editorial changes to fit the volunteer context, e.g. replacing 'to work' with 'to volunteer'. Respondents were asked to respond, using a five-point scale ranging from 'strongly disagree' to 'strongly agree', to the given statements. Sample items associated with the TrPC included the following: "I prefer to volunteer a strictly defined set of hours" and "I expect to benefit from 
any extra effort I put in". Sample items associated with the RelPC included the following: "I feel part of a team in this organisation" and "I feel this organisation reciprocates the effort put in by its volunteers". A respondent's score for each PC type was computed by averaging responses to the relevant set of items (each $\alpha=0.70$ ).

The PsyCap variable was measured with the Psychological Capital Questionnaire (PCQ), a 24-item self-rating instrument developed by Luthans et al. (2007b). As required under the conditions permitting its use, the instrument was administered in its exact form without any changes to the instructions and the 6-point scale ranging from 'strongly disagree' to 'strongly agree' $(\alpha=0.92)$. The language used in the PCQ is generally context-neutral and was therefore not considered in need of adaptation to the volunteer context. In addition, the suitability of the PCQ for the volunteer context was reviewed and confirmed by the organisation's senior volunteer management. As a precaution, however, respondents were instructed explicitly in the accompanying project information sheet to respond to all questions in the survey questionnaire in relation to their volunteer job.

In line with the well-established theories of reasoned action and planned behaviour (Ajzen, 1991), behavioural intentions (EVLN) were measured using an established instrument developed by Naus et al. (2007). Rather than having respondents respond simply to items that are couched in abstract terms (and therefore possibly making them meaningless for some if not all respondents), volunteers were first asked to read an introductory statement and to consider how they would most likely respond. The statement was designed to establish a standardised scenario of non-fulfilment, through references to general circumstances identified in the literature that individuals might perceive as representing non-fulfilment (e.g. 'unreasonable or contradictory demands', 'lack of support' and the 'organisation has not lived up to its side of the deal'), and to reduce the extent to which respondents had to impute information themselves (Alexander and Becker, 1978). This level of description was consistent with the use of the predominant PC type as an independent variable, and our focus on the individual's response intention post-realisation of non-fulfilment. It also avoided the possibility that more explicit examples of non-fulfilment using specific content items might not have resonated with each respondent as either relevant and/or of sufficient weight in themselves to reflect non-fulfilment, a likely outcome given the idiosyncratic nature of the content of an individual's PC (Rousseau, 1995) and the lack of an existing consensus about what specific content items would characterise a volunteer PC (Nichols, 2013). Moreover, the EVLN survey items and introductory scenario were pretested for content face validity with the organisation's senior volunteer management. The pretest resulted in only minor editorial changes to fit the volunteer context.

Following the introductory statement, respondents were presented, with the 20 statements covering the four behavioural response types (EVLN). Respondents were asked to indicate their response using a five-point scale ranging from 'strongly disagree' to 'strongly agree'. A separate score for each behavioural response type was gained by averaging responses to the relevant items (exit, $\alpha=0.85$; voice, $\alpha=0.78$; loyalty, $\alpha=0.70$; neglect, $\alpha=$ $0.81)$.

\section{ANALYSIS AND RESULTS}

Our theoretical orientation and proposed model framed predominant PC type and PsyCap level in combination (without necessarily implying a moderation effect) as the independent predictor variable, and the four behavioural types of response (EVLN) as the dependent variables; therefore, multivariate analysis of variance (MANOVA) was identified as the most appropriate statistical technique for this study. MANOVA allows for comparison between multiple groups, and enables the determination of whether the mean differences between 
groups on a set of dependent variables are likely to have occurred by chance. MANOVA also provides univariate results for each of the four dependent variables separately. Because dependent variables are able to be tested simultaneously, MANOVA controls or adjusts for the risk of a 'type I error' (i.e. incorrect rejection of a true null hypothesis), an error that can mislead researchers to conclude that significant differences exist between groups when in reality they do not (Pallant, 2007). In addition, the requirement that the number of cases in each cell be more than the number of dependent variables (i.e. greater than four in this study) was met.

Given the cross-sectional, self-reported nature of our data, common method variance could augment relationships between the variables in data analysis. To test whether this was a problem, Harman's single-factor test was performed through an exploratory factor analysis. All of the individual items measured for the variables included in our model were entered into an exploratory factor analysis to determine the number of factors that are necessary to account for the variance in the variables. The analysis revealed the presence of 13 distinct factors with eigenvalues greater than 1 , together accounting for 60 per cent of the total variance, thus suggesting that common method variance was not a serious problem in this study (Podsakoff et al., 2003).

Prior to data analysis and hypothesis testing, preliminary data coding for the independent variable was required. First, to determine the respondent's predominant PC type, respondents' scores on each subscale were standardised and the dimension with the highest average score was used. For example, if the relational subscale score was the higher of the two standardised scores, then the respondent's PC type was classified as PreRelPC. Each respondent's predominant PC type was then coded accordingly as a nominal variable. Second, classification of respondents as having either high or low PsyCap was done using a mean split. Each respondent's PsyCap level was coded as a nominal variable, with scores at or below the mean of all respondents' PsyCap scores (4.67) and scores greater than the mean signified as a high PsyCap level. In order to create the required combinations, respondents' predominant PC types and PsyCap levels were subsequently joined to form a four-group categorical variable: (a) PreRelPC with low PsyCap, (b) PreRelPC with high PsyCap, (c) PreTrPC with low PsyCap and (d) PreTrPC with high PsyCap.

Analysis of the survey responses after this coding process indicated that 91.9 per cent reported a PreRelPC, with only 8.1 per cent of respondents reporting a PreTrPC. With regard to PsyCap level, the overall balance was more even with 51.2 per cent of respondents classified as high PsyCap and 48.8 per cent classified as low PsyCap. For respondents reporting a PreRelPC, 51.8 per cent were classified as high PsyCap, compared with only 27.3 per cent of those reporting a PreTrPC classified as high PsyCap.

\section{Insert TABLE 2 MANOVA and ANOVA results for differences between four PC/PsyCap groups}

\section{MANOVA results}

MANOVA was performed to compare the four groups of PC type and PsyCap level on the range of four behavioural responses. The MANOVA results, as shown in Table 2, revealed a statistically significant pattern of responses between the four groups of PC type and PsyCap level at $p<0.001$ : Wilks' lambda $=0.80(F=10.54)$; Pillai's trace $=0.20(F=10.03)$; Hotelling's trace $=0.24(F=10.98)$.

To understand the underlying contributions of the four behavioural response types to the significant multivariate effect, each response type (dependent variable) was then tested using a one-way analysis of variance (ANOVA) with the four groups of PC type and PsyCap level constituting the categorical independent variable. The ANOVA results (Table 2) show 
that the differences between the four groups were significant $(p<0.001)$ on three of the four behavioural response types: voice $(F=33.20)$, exit $(F=6.83)$ and neglect $(F=14.73)$. No significant differences between the four groups were observed in regard to loyalty, however.

Specifically, the study findings indicate that individuals with a PreRelPC and high PsyCap were more likely (compared with the other three groups) to respond initially through voice $[\mathrm{M}=4.21$, standard deviation (SD) $=0.53]$, providing support for Hypothesis 1 . Individuals with a PreTrPC and high PsyCap were more likely to respond initially through exit $(\mathrm{M}=2.82, \mathrm{SD}=0.96)$, providing support for Hypothesis 2 . In contrast, individuals with a PreTrPC and low PsyCap were more likely to respond initially through neglect $(\mathrm{M}=2.64$, $\mathrm{SD}=0.88$ ), providing support for Hypothesis 4 . However, as ANOVA did not produce significant results for loyalty, Hypothesis 3 (individuals with a PreRelPC and low PsyCap are more likely to respond through loyalty) was not supported. This suggests that PC type and the level of PsyCap did not influence respondents' behavioural response towards loyalty.

\section{DISCUSSION}

This study focused on the relationship between volunteers and their organisation, with the aim of testing a unique theoretical model predicting the likelihood of different responses as a function of the combination of a volunteer's level of PsyCap and predominant PC type.

Extant theoretical and empirical research studies were used to develop a series of four hypotheses. Overall, our findings provide support for three of the four hypotheses, and to that extent the findings are consistent with and extend previous theoretical and empirical work in the fields of PC and PsyCap research.

Taking the unsupported hypothesis (Hypothesis 3) first, there are several possible explanations for the higher than expected strength of the voice response. One obvious possibility may be that it simply reflects the very high proportion of respondents (91.9 per cent) in the sample reporting a PreRelPC, which research has demonstrated is associated with a positive constructive attitude towards maintaining the worker-organisation relationship. Another explanation may be found in the nature of the motivational drivers of individuals. Service to their own local community is a strong motivational driver for emergency services volunteers (Esmond, 2009). Therefore, strength of community commitment may lead to an unwillingness to remain passive (Thompson and Bunderson, 2003). Also, as volunteers have no personal economic need to remain with the organisation, they also may be less willing to remain silent when organisational actions are perceived as undermining their capacity to serve their community. A further possible explanatory factor may be drawn from research into personality factors associated with volunteering. Wilson (2012) suggests that individuals with more resilient and extraverted personalities are more likely to volunteer. This suggests that volunteers are more likely to have greater self-assurance which, when joined with feelings of solidarity with other volunteers in a work group drawn from their local community, means participation is less likely to be hindered by feelings of low self-esteem and other negative self-perceptions (Wilson, 2012). In addition, given the increased emphasis on communication and worker participation generally in management practices today, heightened levels of voice should not be a surprise. As many of the volunteers in the study perform front-line duties, they are well equipped to provide constructive, first-hand feedback on the effectiveness of service delivery (Garner and Garner, 2011).

For the other three hypotheses that were supported, our findings are consistent with PC research generally (e.g. McLean Parks and Smith, 1998; Turnley and Feldman, 1999; Raja et al., 2004), and specifically in regard to volunteers (e.g. Liao-Troth, 2005; Taylor et al., 2006; Nichols and Ojala, 2009; Garner and Garner, 2011). They are also consistent with the much less extensive research that has explored the connection between PsyCap and responses by 
individuals to adverse events in the workplace (e.g. Stajkovic and Luthans, 1998; Avey et al., 2011).

Our study findings have research implications. First, they bring together two previously unlinked theoretical concepts - the PC and PsyCap - that share a common aim of furthering understanding of the individual-organisation relationship and how it might be better managed. Second, the results provide empirical support for further examination of how individual differences in positive psychological attributes impact on an individual's PC. In terms of implications in relation to volunteer management, our data also reinforce the importance of sustaining functional relationships, in which leaders and volunteers have the necessary PsyCap to perform their roles in an interdependent and synergistic fashion, and thus enhance performance and productivity. The study findings highlight the potential value of PsyCap development interventions designed to improve volunteer positivity as one of a number of strategies for managing and enhancing volunteer-organisation relationships. While volunteering in general has been associated with better mental health, much of this research has neglected the role of individual differences. Also, emergency services work can be emotionally demanding; hence, its impact on the mental health of volunteers is a potentially fruitful area for future research. In addition, the role of interventions in relation to promoting mental health in emergency services volunteering, which in turn might strengthen the volunteer-organisation relationship and lessen perceptions of PC non-fulfilment, thus warrants further study.

Other actions for managing volunteers, and reducing the negative consequences of a breakdown in the volunteer-organisation relationship, include processes for monitoring emotions and behaviours displayed by volunteers, and drawing reasoned inferences about a volunteer's psychological state. For example, displays of confidence and resilience, pride in the organisation and themselves, and excitement about volunteering may reflect volunteers' perceptions that organisational PC obligations are being met; frustration, cynicism and a lack of initiative may reflect the opposite. Value congruence, participative performance management, effective two-way communication, volunteer welfare and assistance programmes, and authentic leadership development are just a few steps that organisations can take to build and sustain positive relationships in workplaces. On this point, we believe our model has potential as the basis for a diagnostic tool that managers might use to determine an organisational profile to aid in strategic decision making for HRM functions, such as recruitment, training and development, and change management. However, further refinement to clarify how similarities/differences between paid and unpaid workers might affect the model, and then the testing of a revised model, is clearly required before such potential might be realised.

\section{Limitations and future research directions}

The findings reported here are not without limitation. The response rate, while typical compared with other studies of volunteer workers (Tuckey et al., 2012), was relatively low at approximately 25 per cent. The study sample comprised unpaid workers in a single public sector organisation performing a type of work that often entails quite extreme psychological and physical loads on individual volunteers. These study characteristics raise issues concerning the generalisability of the findings to other forms of less demanding voluntary work, other types of volunteer-based organisations and paid workers. In addition, the study was conducted using cross-sectional, self-reported data, which raises concern about the possibility of participants underreporting the frequency of the destructive responses of exit and neglect in order to portray a favourable image.

Moreover, it should be acknowledged that the set of relationships between the variables (predominant PC type, PsyCap and EVLN) represented in our theoretical model was 
simplistic, and deliberately so given this is the first known study to twin the concepts. However, responses to organisational action perceived as non-fulfilment may be shaped by the influence of other bilateral (or multilateral) combinations of a more complex range of variables at the group and organisational levels, including contextual factors like organisational culture, teamwork, leadership styles and management practices, as well as variables at the individual level such as personality, motivation and job satisfaction. Moreover, there is the possibility that likely initial response may differ depending on the nature of the specific content item(s) for which non-fulfilment by the organisation, framed using the concepts of 'breach' or 'violation' (Morrison and Robinson, 1997), is perceived. For example, in the case of the volunteer PC, non-fulfilment of specific value-based obligations may generate a much stronger affective response than non-fulfilment of other types of obligations. Also, a more complex model could recognise the possibility that responses to non-fulfilment may be influenced by the individual's attributions regarding the cause of the organisation's action; deliberate reneging by the organisation can lead to a more intensive affective reaction, thereby possibly resulting in a different type of response. On a related point, this study did not consider either the history of non-fulfilment as a factor in shaping response or how the relationship between non-fulfilment and likely response might change over time. Finally, further development of the theoretical model to describe a more complex set of variables and data relationships using continuous data would enable a range of alternative data analysis techniques, such as structural equation modelling, to be explored.

The simplicity of our model is in part made necessary by the limited amount of extant research into the 'volunteer PC'. We suggest that many of the questions that this study begs in relation to the volunteer PC cannot be properly addressed until consensus develops about several key questions: specifically (a) whether the 'ideology-infused' PC is a conceptually distinct type of PC with specific relevance to volunteers, (b) whether the volunteer PC has the same bidimensional content focus as that of the paid worker, and if so which items are common, (c) whether there are other specific content items (e.g. values-based obligations) that characterise the volunteer PC as different from that of the paid worker, and (d) whether the established concepts of 'breach' and 'violation', that have been developed in the context of paid work (Morrison and Robinson, 1997), are valid for understanding volunteer responses to and outcomes arising from a failure by the organisation to fulfil its obligations under the volunteer PC.

In summary, we believe this study has two important outcomes: (a) it extends both PC and PsyCap research in a novel direction by showing how individuals' beliefs about the worker-organisation relationship, in combination with their level of positivity, might be modelled and used to understand likely responses to organisational actions perceived as unsupportive of the relationship, and (b) it raises a set of interesting issues that might serve as a research agenda for those interested in exploring the dynamics of the worker-organisation relationship in the volunteer context. 


\section{REFERENCES}

Ajzen, I. (1991). 'The theory of planned behaviour'. Organizational Behavior and Human Decision Processes, 50: 2, 179-211.

Alexander, C.S. and Becker, H.J. (1978). 'The use of vignettes in survey research'. Public Opinion Quarterly, 42: 1, 93-104.

Armstrong, J. and Overton, T. (1977). 'Estimating non-response bias in mail surveys'. Journal of Marketing Research, 14: 3, 396-402.

Avey, J.B., Luthans, F. and Jensen, S.M. (2009). 'Psychological capital: a positive resource for combating employee stress and turnover'. Human Resource Management, 48: 5, 677-693.

Avey, J.B., Reichard, R.J., Luthans, F. and Mhatre, K.H. (2011). 'Meta-analysis of the impact of positive psychological capital on employee attitudes, behaviors, and performance'. Human Resource Development Quarterly, 22: 2, 127-152.

Bal, P.M., DeLange, A.H. and Jansen, P.G.W. (2007). 'Psychological contract breach and job attitudes: a meta-analysis of age as a moderator'. Journal of Vocational Behavior, 72: $1,143-158$.

Bandura, A. (2006). 'Toward a psychology of human agency'. Perspectives on Psychological Science, 1: 2, 164-180.

Chen, D.J. and Lim, V.K.G. (2012). 'Strength in adversity: the influence of psychological capital on job search’. Journal of Organizational Behavior, 33: 6, 811-839.

Clary, E.G., Snyder, M., Ridge, R.D., Copeland, J., Stukas, A., Haugen, J. and Miene, P. (1998). 'Understanding and assessing the motivations of volunteers: a functional approach'. Journal of Personality and Social Psychology, 74: 6, 1516-1530.

Conway, N. and Briner, R.B. (2009). 'Fifty years of psychological contract research: what do we know and what are the main challenges?', in G.P. Hodgkinson and J.K. Ford (eds), International Review of Industrial and Organizational Psychology, Chichester: Wiley.

Edwards, J.C., Rust, K.G., McKinley, W. and Moon, G. (2003). 'Business ideologies and perceived breach of contract during downsizing: the role of the ideology of employee self-reliance'. Journal of Organizational Behavior, 24: 1, 1-23.

Esmond, J. (2009). Report on the attraction, support and retention of emergency management volunteers. Australian Emergency Management, Canberra.

Farmer, S.M. and Fedor, D.B. (1999). 'Volunteer participation and withdrawal: a psychological contract perspective on the role of expectations and organisational support'. Nonprofit Management and Leadership, 9: 4, 349-367.

Garner, J.T. and Garner, L.T. (2011). 'Volunteering an opinion: organisational voice and volunteer retention in non-profit organisations'. Nonprofit and Voluntary Sector Quarterly, 40: 5, 813-828.

Hirschman, A.O. (1970). Exit, Voice, and Loyalty: Responses to Decline in Firms, Organisations, and States, Cambridge, MA: Harvard University Press.

Jackson, D., Firtko, A. and Edenborough, M. (2007). 'Personal resilience as a strategy for surviving and thriving in the face of workplace adversity: a literature review'. Journal of Advanced Nursing, 60: 1, 1-9.

Khan, A., Siraj, S. and Li, L.P. (2011). 'Role of positive psychological strengths and "big five” personality traits in coping mechanism of university students'. International Conference on Humanities, Society and Culture, 20, 210-215.

Larson, M. and Luthans, F. (2006). 'Potential added value of psychological capital in predicting work attitudes’. Journal of Leadership and Organisational Studies, 13: 2, 75-92. 
Laschinger, H.K.S. and Grau, A.L. (2012). 'The influence of personal dispositional factors and organizational resources on workplace violence, burnout, and health outcomes in new graduate nurses: a cross-sectional study'. International Journal of Nursing Studies, 49: 3, 282-291.

Liao-Troth, M.A. (2005). 'Are they here for the long haul? The effects of functional motives and personality factors on the psychological contracts of volunteers'. Nonprofit and Voluntary Sector Quarterly, 34: 4, 510-530.

Luthans, F., Avolio, B.J., Avey, J.B. and Norman, S. (2007a). 'Positive psychological capital: measurement and relationship with performance and satisfaction'. Personnel Psychology, 60: 3, 541-572.

Luthans, F., Luthans, K.W. and Luthans, B.C. (2004). 'Positive psychological capital: going beyond human and social capital'. Business Horizons, 47: 1, 45-50.

Luthans, F., Norman, S.M., Avolio, B.J. and Avey, J.B. (2008). 'The mediating role of psychological capital in the supportive organizational climate-employee performance relationship'. Journal of Organizational Behavior, 29: 2, 219-238.

Luthans, F. and Youssef, C.M. (2004). 'Human, social and now positive psychological capital management'. Organizational Dynamics, 33: 2, 143-160.

Luthans, F., Youssef, C.M. and Avolio, B.J. (2007b). Psychological Capital: Developing the Human Competitive Edge, Oxford: Oxford University Press.

Masten, A.S. (2001). 'Ordinary magic: resilience process in development'. American Psychologist, 56: 3, 227-239.

McLean Parks, J. and Smith, F.L. (1998). 'Organizational contracting, a "rational” exchange?’, in J.J. Halpern and R.N. Stern (eds), Debating Rationality, Ithaca, NY: Cornell University Press.

Millward, L.J. and Hopkins, L.J. (1998). 'Psychological contracts: organizational and job commitment'. Journal of Applied Psychology, 28: 16, 1530-1556.

Morrison, E.W. and Robinson, S.L. (1997). 'When employees feel betrayed: a model of how psychological contract develops'. Academy of Management Review, 22: 1, 226-256.

Naus, F., Van Iterson, A. and Roe, R. (2007). 'Organizational cynicism: extending the exit, voice, loyalty and neglect model of employees’ responses to adverse conditions in the workplace'. Human Relations, 60: 5, 683-718.

Nichols, G. (2013). 'The psychological contract of volunteers: a new research agenda'. Voluntas: International Journal of Voluntary and Nonprofit Organizations, 24: 4, 9861005.

Nichols, G. and Ojala, E. (2009). 'Understanding the management of sports events volunteers through psychological contract theory'. Voluntas: International Journal of Voluntary and Nonprofit Organizations, 20: 4, 369-387.

O’Donohue, W. and Nelson, L. (2009). 'The psychological contracts of Australian hospital volunteer workers'. Australian Journal on Volunteering, 19: 9, 1-11.

Pallant, J. (2007). SPSS: Survival Manual: A Step-by-Step Guide to Data Analysis Using SPSS for Windows, Version 15, NSW, Australia: Allen \& Unwin.

Podsakoff, P.M., MacKenzie, S.M., Lee, J. and Podsakoff, N.P. (2003). 'Common method variance in behavioural research: a critical review of the literature and recommended remedies'. Journal of Applied Psychology, 88: 5, 879-903.

Raja, U., Johns, G. and Ntalianis, F. (2004). 'The impact of personality on psychological contracts'. Academy of Management Journal, 47: 3, 350-367.

Rousseau, D.M. (1995). Psychological Contracts in Organizations, Thousand Oaks, CA: Sage Publications. 
Scheel, T. and Mohr, G. (2013). 'The third dimension: value-oriented contents in psychological contracts'. European Journal of Work and Organizational Psychology, 22: 4, 390-407.

Snyder, C. and Lopez, S. (eds) (2002). Handbook of Positive Psychology, Oxford: Oxford University Press.

Stajkovic, A. and Luthans, F. (1998). 'Self-efficacy and work-related performance: a metaanalysis’. Psychological Bulletin, 124: 2, 240-261.

Starnes, B.J. (2007). 'An analysis of psychological contracts in volunteerism and the effect of contract breach on volunteer contributions to the organization'. International Journal of Volunteer Administration, 24: 3, 31-41.

Suazo, M.M., Turnley, W.H. and Mai-Dalton, R.R. (2005). 'The role of perceived violation in determining employees' reactions to psychological contract breach'. Journal of Leadership and Organizational Studies, 12: 1, 24-36.

Taylor, T., Darcy, S., Hoye, R. and Cuskelly, G. (2006). 'Using psychological contract theory to explore issues in effective volunteer management'. European Sport Management Quarterly, 6: 2, 123-147.

Thompson, J.A. and Bunderson, J.S. (2003). 'Violations of principle: ideological currency in the psychological contract'. Academy of Management Review, 29: 4, 571-586.

Thormar, S.B., Gersons, B., Juen, B., Marschang, A., Djakababa, M.N. and Olff, M. (2010). 'The mental health impact of volunteering in a disaster setting: a review'. Journal of Nervous and Mental Disease, 198: 8, 529-538.

Tuckey, M.R., Bakker, A. and Dollard, M.F. (2012). 'Empowering leaders optimize working conditions for engagement: a multilevel study'. Journal of Occupational Health Psychology, 17: 1, 15-27.

Turnley, W.H. and Feldman, D.C. (1999). 'The impact of psychological contract violations on exit, voice, loyalty, and neglect'. Human Relations, 52: 7, 895-922.

Vantilborgh, T., Bidee, J., Pepermans, R., Willems, J., Huybrechts, G. and Jegers, M. (2011). 'A new deal for NPO governance and management: implications for volunteers using psychological contract theory'. Voluntas: International Journal of Voluntary and Nonprofit Organizations, 22: 4, 639-657.

Vantilborgh, T., Bidee, J., Pepermans, R., Willems, J., Huybrechts, G. and Jegers, M. (2012). 'Volunteers' psychological contracts: extending traditional views'. Nonprofit and Voluntary Sector Quarterly, 41: 6, 1072-1091.

Vantilborgh, T., Bidee, J., Pepermans, R., Willems, J., Huybrechts, G. and Jegers, M. (2014). 'Effects of ideological and relational psychological contract breach and fulfilment on volunteers' work effort'. European Journal of Work and Organizational Psychology, 23: 2, 217-230.

Wilson, J. (2012). 'Volunteerism research: a review essay'. Nonprofit and Voluntary Sector Quarterly, 41: 2, 176-212.

Winkel, D.E., Wyland, R.L., Shaffer, M.A. and Clason, P. (2011). 'A new perspective on psychological resources: unanticipated consequences of impulsivity and emotional intelligence'. Journal of Occupational and Organizational Psychology, 84: 1, 78-94.

Zhao, H., Wayne, S.J., Glibkowski, B.C. and Bravo, J. (2007). 'The impact of psychological contract breach on work-related outcomes: a meta-analysis'. Personnel Psychology, 60: 4, 647-680. 
Table 1: Interpretive framework for psychological contracts

\begin{tabular}{|c|c|c|c|}
\hline $\begin{array}{l}\text { Contract } \\
\text { type }\end{array}$ & Transactional PC & (Ideology-infused) & Relational PC \\
\hline $\begin{array}{c}\text { Salient } \\
\text { beneficiary }\end{array}$ & Self & $\begin{array}{c}\text { Society, some segment } \\
\text { thereof, or an } \\
\text { intangible principle }\end{array}$ & $\begin{array}{r}\text { Joint (Self and } \\
\text { organizational } \\
\text { community) }\end{array}$ \\
\hline Content focus & $\begin{array}{l}\text { Economic, material } \\
\text { e.g. pay in exchange } \\
\text { for hours worked }\end{array}$ & $\begin{array}{l}\text { Ideological e.g. social } \\
\text { values and work values }\end{array}$ & $\begin{array}{r}\text { Socio-emotional, non- } \\
\text { material e.g. job } \\
\text { security in exchange } \\
\text { loyalty }\end{array}$ \\
\hline $\begin{array}{l}\text { Organisation's } \\
\text { obligations }\end{array}$ & $\begin{array}{l}\text { Provide continued } \\
\text { work, safe working } \\
\text { environment, fair } \\
\text { compensation }\end{array}$ & $\begin{array}{c}\text { Demonstrate credible } \\
\text { commitment to valued } \\
\text { social cause }\end{array}$ & $\begin{array}{r}\text { Provide training, career } \\
\text { development, } \\
\text { promotion } \\
\text { opportunities, job } \\
\text { security }\end{array}$ \\
\hline $\begin{array}{l}\text { Individual's } \\
\text { obligations }\end{array}$ & $\begin{array}{l}\text { Fulfil specified } \\
\text { requirements }\end{array}$ & $\begin{array}{c}\text { Participate in } \\
\text { organization's } \\
\text { mission/cause; } \\
\text { organizational and } \\
\text { societal citizenship } \\
\text { behaviour }\end{array}$ & $\begin{array}{r}\text { Fulfil generalised } \\
\text { requirements, loyalty, } \\
\text { commitment, } \\
\text { organisational } \\
\text { citizenship behaviour }\end{array}$ \\
\hline $\begin{array}{l}\text { Scope and } \\
\text { tangibility }\end{array}$ & $\begin{array}{l}\text { Narrow, specific, } \\
\text { observable, non- } \\
\text { flexible reciprocity }\end{array}$ & & $\begin{array}{r}\text { Pervasive, less specific, } \\
\text { subjective, flexible } \\
\text { reciprocity }\end{array}$ \\
\hline $\begin{array}{c}\text { Stability and } \\
\text { duration }\end{array}$ & $\begin{array}{l}\text { Static, close-ended, } \\
\text { specific time frame }\end{array}$ & & $\begin{array}{l}\text { Dynamic, open-ended } \\
\text { indefinite time frame }\end{array}$ \\
\hline
\end{tabular}

Source: Adapted from McLean Parks and Smith (1998), Rousseau (1995) and Thompson and Bunderson (2003) 
Figure 1: Relating predominant Psychological Contract type and level of Psychological Capital to EVLN responses

\begin{tabular}{cc|c|c|c}
\multicolumn{2}{c}{} & \multicolumn{2}{c|}{ Passive } & \multicolumn{2}{c}{ Active } \\
\cline { 2 - 4 } $\begin{array}{c}\text { Predominant } \\
\text { PC Type }\end{array}$ & Relational & LOYALTY & VOICE & Constructive \\
\cline { 3 - 4 } & Transactional & NEGLECT & EXIT & \multirow{2}{*}{ Destructive } \\
\cline { 3 - 4 } & & Low & High
\end{tabular}

PsyCap Level 
Table 2: MANOVA and ANOVA results for differences between four PC/PsyCap groups

\begin{tabular}{|c|c|c|c|c|c|c|}
\hline \multirow[b]{2}{*}{ Dependent variable } & \multicolumn{4}{|c|}{ Group Mean ${ }^{*}$} & \multirow[b]{2}{*}{$\boldsymbol{F}$} & \multirow[b]{2}{*}{$\boldsymbol{P}$} \\
\hline & $\begin{array}{c}\text { PreRelPC } \\
\text { and } \\
\text { High } \\
\text { PsyCap }\end{array}$ & $\begin{array}{c}\text { PreRelPC } \\
\text { and } \\
\text { Low } \\
\text { PsyCap }\end{array}$ & $\begin{array}{c}\text { PreTrPC } \\
\text { and } \\
\text { High } \\
\text { PsyCap }\end{array}$ & $\begin{array}{c}\text { PreTrPC } \\
\text { and } \\
\text { Low } \\
\text { PsyCap }\end{array}$ & & \\
\hline Voice & $4.21(0.53)$ & $3.76(0.53)$ & $3.93(1.06)$ & $3.58(0.66)$ & 33.20 & $<0.001$ \\
\hline Exit & $2.16(0.90)$ & $2.30(0.69)$ & $2.82(0.96)$ & $2.20(0.88)$ & 6.83 & $<0.001$ \\
\hline Loyalty & $2.86(0.81)$ & $2.90(0.64)$ & $2.72(0.82)$ & $3.11(0.76)$ & 1.34 & 0.260 \\
\hline Neglect & $1.78(0.78)$ & $1.98(0.64)$ & $2.08(0.81)$ & $2.64(0.88)$ & 14.73 & $<0.001$ \\
\hline \multicolumn{7}{|l|}{ Multivariate tests } \\
\hline Wilks’ Lambda=0.80 & & & & & 10.54 & $<0.001$ \\
\hline Pillai's Trace $=0.20$ & & & & & 10.03 & $<0.001$ \\
\hline Hotelling's Trace $=0.24$ & & & & & 10.98 & $<0.001$ \\
\hline
\end{tabular}

